\title{
Determination of major bioactive compounds from olive leaf
}

Ángeles Guinda*a , José María Castellano ${ }^{\mathrm{a}}$, José Manuel Santos-Lozano ${ }^{\mathrm{bc}}$, Teresa Delgado-Hervás ${ }^{\mathrm{a}}$, Pilar Gutiérrez-Adánez ${ }^{\mathrm{a}}$ and Mirela Rada ${ }^{\mathrm{a}}$

${ }^{\mathrm{a}}$ Food and Health Department, Instituto de la Grasa - CSIC. Universidad Pablo de Olavide Edificio 46. 41013-Seville. Spain.

${ }^{\mathrm{b}}$ CIBER Fisiopatología de la Obesidad y Nutricion (ciberobn), Instituto de Salud Carlos III, Madrid, Spain.

${ }^{\mathrm{c}}$ Deparment of Family Medicine, San Pablo Health Center, Primary Care Division of Seville, Andalusian Health Service \& Deparment of Medicine, University of Seville, Spain

*Corresponding author: Tel.: +34954611550 (ext. 237); Fax: +34954616790

$$
\begin{aligned}
\text { E-mail address: } & \text { guinda@ig.csic.es (Á. Guinda)* } \\
& \text { jmcas@ig.csic.es (J.M. Castellano) } \\
& \text { josemanuel.santos@ono.com (J.M. Santos-Lozano) } \\
& \text { tdelgado@ig.csic.es (T. Delgado) } \\
& \text { pgmafili@hotmail.com (P.Gutiérrez-Adánez) } \\
& \text { mrada@ig.csic.es (M. Rada) }
\end{aligned}
$$




\section{ABSTRACT}

Olive leaves are an agricultural residue resulting from the pruning of olive trees that may be considered an available industrial byproduct. The olive tree is biochemically characterized for the presence of secoiridoids, carbohydrates, sugar alcohols, and terpenoids. Oleuropein, especially abundant in the olive leaves (up to $14 \% \mathrm{DW}$ ), have the greatest biological interest. The polyalcohol mannitol, which represents approx. a 3\% of the leaf dry weight, has been used by the food and pharmaceutical industries as excipient, due to its high sweetness and poor caloric power. Likewise, oleanolic acid is present in the olive leaf in significant concentrations $(\approx 3 \% \mathrm{DW})$ and has been endorsed with very important pharmacological properties. In this work we describe a novel procedure for the determination of the major bioactive compounds from the olive leaf by SPE and HPLC. These bioactive compounds were determined in the four most significant Spanish Olea europaea cultivars. Olive leaf contains important amounts of oleanolic acid, oleuropein and mannitol, whose recovery could be interesting for the pharmaceutical, cosmetics and food industries. The analytical methodology presented in this work would serve as a very suitable tool for the control of any industrial process designed to obtain these high added-value compounds.

Keywords: Olea europaea L., oleanolic acid, oleuropein, hydroxytyrosol, mannitol. 


\section{INTRODUCTION}

The accumulation and managing of residues from the agricultural and food industries represent a serious problem from the economic and environmental points of view. Nevertheless, the valorization of such by-products for the recovery and/or biotransformation of their organic matter emerges as a relevant opportunity that changes the mere waste treatment in a process for the obtaining of high added value products. Olive leaf is one of the most important agricultural biomass in Spain. A typical olive tree pruning batch includes $70 \%$ thin branches (by weight, with approx. one-third made up of leaves). In Spain, the current annual production of this biomass is estimated in more than $7 \times 10^{6}$ ton $\left(3000 \mathrm{~kg} \mathrm{ha}^{-1} \mathrm{year}^{-1}\right)$, representing approximately $30 \%$ of the world olive pruning production (Manzanares et al., 2011). The leaves may also be considered an easily available industrial byproduct, since they arrive to the olive mills in appreciable quantities, around $5 \%$ of the total weight of olives. Usually the residues are disposed of either by burning or by grinding and scattering on the field, causing economic and environmental problems. In this context, the utilization of olive leaf as raw material for the obtaining of added-value compounds is a promising option to increase the profitability of the olive groves.

The composition of ethanolic extracts from olive leaf is object of special attention due to the presence in significant concentrations of bioactive compounds, such as phenolic derivatives, alditols and pentacyclic triterpenes, all of them with very interesting pharmacological properties (Guinda et al., 2006; Erba and Icier 2010). The main triterpene from the olive leaf is oleanolic acid (3.0-3.5\% DW), followed by significant concentrations of maslinic acid and minor levels of ursolic acid, erythrodiol, and uvaol. The literature on the biological activity of oleanolic acid is extended, and its pharmacological importance has been stood out (Liu et al., 2007; Tsai and Yin 2008; Martin et al., 2010). Our research group has postulated a vision of the molecular mechanisms of the therapeutic action of oleanolic acid 
against diabetes and metabolic syndrome (Castellano et al., 2013). Recently, a mini-review on preclinical rodents' models of cancer has reported that OA obtained from natural plant materials inhibits the tumor cell proliferation, induces apoptosis, and prevents angiogenesis, as well as the invasion and metastasis (Shanmugam et al., 2014). All of these considerations amply justify the recovery of oleanolic acid from the olive leaf.

Among the phenolic derivatives present in the olive leaf, oleuropein (OU) and the products of its hydrolysis are those of the greatest biological interest. The oleuropein content is very high, around $8-14 \%$ DW (Silva et al., 2006). OU is endorsed with several pharmacological properties, including the antioxidant, anti-inflammatory, anti-atherogenic, anti-cancer, antimicrobial, and antiviral activities (Visioli et al., 2002; Carluccio et al., 2003; Tripoli et al., 2005). In addition, oleuropein has been shown to be cardioprotective and has been shown to exhibit anti-ischemic and hypolipidemic activities (Andreadou et al., 2006; Singh et al., 2008). A specific review of the pharmacology effects of olive biophenols has also been published (Obied et al., 2012).

Mannitol (Ma), a naturally occurring polyol, is present in significant concentrations $(3 \%)$ in ethanolic extracts from olive leaf (OLE). In humans, the ingestion of sugar alcohols is known to reduce the postprandial rise in blood glucose and insulin response, because of their slow enteric absorption, and also because their metabolism is not dependent from insulin. Consequently, many foods based on sugar alcohols have been used safely in the diets for diabetics. Ma is a food additive permitted on an interim basis by the Food \& Drug Administration (FDA) (Guidance CDER/FDA 2000). Furthermore, mannitol is a scavenger of hydroxyl radicals and a low-calorie sweetener (Gaspar et al., 2004). Due of its appropriate properties, mannitol is commonly used in the pharmaceutical formulation of chewable tablets and granulated powders. This alditol is currently produced commercially by chemical 
hydrogenation of sugars. As mannitol is found in a significant amount in the olive leaves, its production from this natural source can be considered as an interesting alternative.

The aim of this work was to develop a novel, reproducible and precise procedure for the determination of the major bioactive compounds from the olive leaf: oleanolic acid, oleuropein and mannitol. This way, we provide an analytical tool to control the processes for obtaining these high-added-value compounds and contribute to the valorization of the olive grove biomass.

This new method was applied to characterize the mayor bioactive compounds from OLE of the most significant Spanish Olea europaea cultivars.

\section{MATERIALS AND METHODS}

Plant materials, solvents, standards and reagents. Olive leaves samples, from the four main Spanish Olea europaea cultivars ('Arbequina', 'Hojiblanca', 'Lechin' and 'Picual') were hand-picked from adult trees (>10 years old) of the "Hacienda Guzmán" olive grove (La Rinconada, Seville-Spain; www.haciendaguzman.com).

Molasses alcohol (Alcoholes del Sur, Córdoba, Spain), syringe filters of $0.20 \mu \mathrm{m}$ (PTFE, Luer-Lock), HPLC grade methanol, ethanol, and acetonitrile, as well as formic acid were purchased from Merck (Darmstadt, Germany). Standards: ursolic acid (purity 90\%), asiatic acid, maslinic acid, uvaol and erythrodiol (purity $\geq 97 \%$ ); sucrose, D-(+)-glucose, D-mannitol, D-sorbitol (purity $\geq 98 \%$ ) and $p$-hydroxyphenyl acetic acid (purity 98\%), were purchased from Sigma Chemical Co (Sigma-Aldrich Company Ltd, Great Britain). Hydroxytyrosol, oleuropein, verbascoside, luteolin-O-glucoside, apigenin7-O-glucoside, ligstroside and oleuropein-aglycone (purity $\geq 97 \%$ ) were purchased from Extrasynthese (Genay CEDEX, France). The oleanolic acid (purity 97\%), employed in this study was obtained in our laboratory from olive leaves in accordance with the procedure described by Guinda et al. 
(2001). Deionized water was obtained from a Milli-Q purification system (Millipore, Bedford, MA, USA). Solid-phase extraction cartridges Strata SDB-L (C18 over a base of poly-styrenedivinylbenzene; $100 \mu \mathrm{m} ; 260 \AA ; 1000 \mathrm{mg} / 6 \mathrm{~mL}$ ) were purchased from Phenomenex Inc (USA).

Extraction procedure. Two grams of milled leaves were homogenized with $40 \mathrm{~mL}$ of ethanol in a Sorvall OMNI MIXER Mod.17106 (DuPont Instruments, Newton, CT, USA), for three min. The ethanolic raw extract was filtered through Whatman paper. Asiatic acid $(500 \mu \mathrm{L}$ of a $1 \mathrm{mg} / \mathrm{mL}$ solution in absolute ethanol), $1 \mathrm{~mL}$ of sorbitol $(1 \mathrm{mg} / \mathrm{mL}$ in ethanol/water 1:1) and $1 \mathrm{~mL}$ of p-hydroxyphenyl acetic acid (PHPA) (1 mg/mL in absolute ethanol), as internal standards for triterpenoids, sugars and phenols determinations, were added to a $1.5 \mathrm{~mL}$ aliquot of the olive leaf extract. Extracts from the each olive cultivar were obtained in three replicates.

Fractionation of terpenoids, phenols and sugars of the ethanolic extract by filtration and SPE. The extracts (standards included) were brought to dryness under reduced pressure at $40^{\circ} \mathrm{C}$, re-suspended in $1.5 \mathrm{~mL}$ of deionized water and filtered through a Luer-Lock filter supporting a PTFE membrane of $0.20 \mu \mathrm{m}$ pore size. The insoluble terpenoids and chlorophyllic pigments were retained in the filtering membrane. Chlorophylls were removed by passing $4 \mathrm{~mL}$ ethanol/water $(1: 1, \mathrm{v} / \mathrm{v})$, and subsequently the triterpenoids were recovered from the filter with $3 \mathrm{~mL}$ of absolute ethanol. An aliquot $(400 \mu \mathrm{L})$ of this ethanolic solution was reduced to dryness and reconstituted in $200 \mu \mathrm{L}$ of acetonitrile $/ \mathrm{H}_{2} \mathrm{O}(85: 15, \mathrm{v} / \mathrm{v}, 0.5 \%$ phosphoric acid), vortex mixed for $30 \mathrm{~s}$, and filtered through a $0.45 \mu \mathrm{m}$ membrane prior to its HPLC analysis.

On the other hand, the filtered aqueous extract containing the phenols and sugars was fractionated by solid phase extraction in a Strata SDB-L cartridge. The SPE column was placed in a vacuum elution apparatus and conditioned by passing of $20 \mathrm{~mL}$ of methanol, followed by drying under moderate vacuum, and $20 \mathrm{~mL}$ of water. Then, $1 \mathrm{~mL}$ of the aqueous 
extract was loaded into the column. A first fraction, containing sugars and polyols, was eluted with $4 \mathrm{~mL}$ of water The SPE column was then washed with $2 \mathrm{~mL}$ of distilled water and dried under moderate vacuum. Subsequently, a second fraction carrying the phenolics was eluted with $6 \mathrm{~mL}$ of methanol and cold stored at $-20{ }^{0} \mathrm{C}$ until its analysis.

GC-MS identification of OLE major biocompounds. An aliquot of the ethanolic extract containing the triterpenoids was reduced to dryness by a nitrogen stream. The residue was silylated with trimethylsilyl trifluoroacetamide (1\% trimethylchlorosilane):pyridine (3:1). Identification of terpenoids was performed using GC-MS, QP2010 Ultra (Shimadzu, Europa $\mathrm{GmbH}$ ) fitted with an AOC-20i autosampler, an ion source of electron impact and a quadrupole detector. The splitless mode was used and the injector temperature was set at $290^{\circ} \mathrm{C}$. Helium as a carrier gas at a pressure of $53.1 \mathrm{kPa}$ and a flow of $1 \mathrm{~mL} / \mathrm{min}$ was used. The oven temperature program was as follow: initial temperature $50^{\circ} \mathrm{C}$ for $1 \mathrm{~min}, 50-200^{\circ} \mathrm{C}$ at $40^{\circ} \mathrm{C} / \mathrm{min}, 200-280^{\circ} \mathrm{C}$ at $10^{\circ} \mathrm{C} / \mathrm{min}$ and finally held for $2 \mathrm{~min}$. Total run time: $14,75 \mathrm{~min}$. The MS conditions were: interface temperature: $280^{\circ} \mathrm{C}$; ion source temperature: $220^{\circ} \mathrm{C}$; electron impact: 70eV; acquisition mode: scan (m/z 50-600). The identification of terpenoids were accomplished by comparing the retention times and abundance ratios of two fragments ions (216 and $203 \mathrm{~m} / \mathrm{z}$ ), specifically, $216 \mathrm{~m} / \mathrm{z}$ for triterpenic dialcohols and $203 \mathrm{~m} / \mathrm{z}$ for triterpenic acids.

For the identification of phenolics, an aliquot of the methanolic SPE-fraction was previously derivatized with pyridine:bis(trimethylsilyl)trifluoracetamide:chlorotrimethylsilane (5:5:1) for $30 \mathrm{~min}$ at $70{ }^{\circ} \mathrm{C}$, and then analyzed by GC-MS according to Justino et al., (2010), on a Shimadzu QP2010 equipped with a capillary column (SPB-5; $30 \mathrm{~m} \times 0.32 \mathrm{~mm} ; 0.25 \mu \mathrm{m}$ film thickness; Supelco, Spain).

The SPE purified sugar fraction was evaporated to dryness and silylated with trimethylchlorosilane and hexamethyldisilazane $(1: 1,1 \mathrm{~mL})$ in dry pyridine $(1 \mathrm{~mL})$ for $1 \mathrm{~h}$ at 
$70^{\circ} \mathrm{C}$. The sugars were identified using the above mentioned GC-MS apparatus according to Kaycee and Kırmızı̈ül (2010).

\section{HPLC determination of terpenoids, sugars and phenols.}

Triterpenes quantification. Triterpenoids from the olive leaf were analyzed by HPLC, using a modification of the method previously described for the determination of triterpenoids in human serum (Rada et al., 2011). The separation and detection were performed with a Merck-Hitachi liquid chromatographic system (Hitachi High-Technologies Europe GmbH, Germany) equipped with a Rheodyne injection valve $\left(20 \mu \mathrm{L}\right.$ loop), a $30^{\circ} \mathrm{C}$ thermostatized $\mathrm{C} 18$ reversed-phase Waters Spherisorb ODS-2 column (250x4.6mm inner diameter, $5 \mu \mathrm{m}$ particle) (Sigma-Aldrich, Spain), and a L4250-UV-Vis detector. The analyte was eluted isocratically at a flow rate of $0.8 \mathrm{~mL} / \mathrm{min}$ with the mobile phase of acetonitrile $/ \mathrm{H}_{2} \mathrm{O}(85: 15, \mathrm{v} / \mathrm{v}, 0.5 \%$ phosphoric acid). The optimum wavelength for determination was $204 \mathrm{~nm}$. Quantification of terpenic acids was realized using asiatic acid as internal standard.

Saccharides and polyols quantification. Quantification of sugars and alditols was carried out by a modification of the method previously established by Romani et al. (1994), which use an isocratic HPLC technique. The separation and detection were performed with a Merck-Hitachi liquid chromatographic system (Hitachi High-Technologies Europe GmbH, Germany) equipped with a refractive index detector L-2490 and a Rheodyne injection valve $(20 \mu \mathrm{L}$ loop). A SUPELCOGEL Ca $(30 \mathrm{~cm} \mathrm{x} 7.8 \mathrm{~mm})$ (Sigma-Aldrich, Spain) ion exchange chromatography column $\left(85^{\circ} \mathrm{C}\right)$ and deionized water as the mobile phase $(0,5 \mathrm{~mL} / \mathrm{min})$ were employed. Quantification of saccharides and polyols was carried out using D-sorbitol as internal standard.

Phenols quantification. Quantification of phenols from the methanolic SPE-fraction was performed by a modification of the method previously described by Rada et al. (2007). An Analytical Photodiode Array Detector (Spectro Monitor 5000. Artisan Technology Group. 
IL, USA), a Rheodyne injection valve $(20 \mu \mathrm{L}$, loop) and a Lichrospher 100RP-18 column 250x4 mm i.d., 5 $\mu \mathrm{m}$ ) (Merck, Darmstadt, Germany) were used. Elution was performed at a flow rate of $1.0 \mathrm{~mL} / \mathrm{min}$ using as mobile phase a mixture of water $(0.1 \%$ formic acid) (solvent A) and methanol/acetonitrile (50:50 v/v at $0.1 \%$ formic acid) (solvent B). The solvent gradient changed according to the following program: from 95 to $70 \%$ solvent $\mathrm{A}$ in $25 \mathrm{~min}$, to $65 \%$ in $5 \mathrm{~min}$, to $40 \%$ in $5 \mathrm{~min}$, to $30 \%$ in $10 \mathrm{~min}$, and $0 \%$ solvent $\mathrm{A}$ in $5 \mathrm{~min}$, followed by $5 \mathrm{~min}$ maintained at $100 \%$ B. Quantification of phenols was carried out at $280 \mathrm{~nm}$ using PHPA as internal standard.

Statistical analysis. All data are presented as the means \pm standard deviation from three independent experiments carried out in triplicates. The data were evaluated by one-way ANOVA with the SigmaStat 3.5 Software (SPSS Inc. Chicago, IL, USA). Comparison of means was assessed using the Tukey's test, and statistical significance was considered at $p>$ 0.05 .

\section{RESULTS AND DISCUSSION}

Extraction and identification of olive leaves bioactive compounds. This study was carried out with the aim of the ecofriendly recovery of pentacyclic triterpenes, bioactive sugars and phenolics from the olive leaf using molasses ethanol $96 \%$ as extracting media. We use this non-toxic and relatively cheap bio-solvent because is a good extracting agent for all the objective compounds, and it's selective to mannitol versus other sugars present in olive leaves. Many of the reported procedures for the extraction of the olive leaf components have used methanol, but the increasing interest in the potential utilization of these compounds in humans invoke the search of protocols based on non-toxic extractants. The advantages of using molasses ethanol were previously shown by us in (Tabera-Galván et al., 2005). 
Figure 1 shows a flow diagram of the analytical procedure established for the determination of bioactive compounds in ethanolic OLE. Performing this protocol the recoveries were: 97$99 \%, 68-81 \%, 95-99 \%$, for terpenes, sugars and phenols, respectively. The identification of OLE major biocompounds were accomplished by GC-MS (previous routine laboratory identifications by HPLC employing the corresponding standards); and their quantification was carried out by modifications of methods previously established in our lab using asiatic acid, PHPA and D-sorbitol as internal standards for triterpenes, phenolics and sugars, respectively (Rada et al., 2007; Guinda et al., 2010). Narrow and symmetrical peaks for all the detected OLE bio-compounds were obtained at the aforementioned chromatographic parameters, and all the internal standards were well distinguished in the conditions that the analysis were carried out. Figure 2 shows a typical HPLC-UV chromatogram of pentacyclic triterpenes from the olive leaf. The major triterpenoid is oleanolic acid, which represents up to $63-69 \%$ of the triterpenic fraction in the four studied olive varieties. Maslinic and ursolic are also present at significant concentrations, ranging between $18-23 \%$ and 6-9\%, respectively. In addition, the triterpenoids dialcohols erythrodiol and uvaol, immediate biosynthetic precursors of oleanolic and ursolic acids, appear as minor components. Figure 4 shows a typical HPLC-IR chromatogram of saccharides and polyols in ethanolic OLE. The mayor saccharide is mannitol, which represents up to $67-80 \%$ of the sugars fraction in the four studied varieties. Sucrose and glucose are other two significant sugars present in the ethanolic extract, with concentrations that ranged between $14-23 \%$ and $5-10 \%$, respectively. Among the group of phenolic compounds extracted with ethanol, oleuropein is clearly the major, representing a $54-56 \%$ of this fraction in the leaves of the four Spanish olive varieties (Figure 4). Peaks 3, 6 and 1 are also present at significant levels (around 12.51 .3 and 7.2\%, respectively), accompanied by 2, 4 and 7 peaks as minor components.

\section{Validation of the methods}


Terpenes recovery. Terpenes were separated from other components of the ethanolic extract using their water insolubility. Thus, when the alcoholic OLE were reduced to dryness, re-suspended in deionized water and filtered through a PTFE membrane of $0.20 \mu \mathrm{m}$ pore size, the insoluble triterpenoids were retained in the filtering membrane. To study the recovery efficiency of this procedure, we used standard oleanolic acid solutions at the concentration range $0.1-1.0 \mathrm{mg} / \mathrm{mL}$. Three levels of concentrations were assayed and each point was analyzed in triplicate by HPLC as indicated in the 2.6.1 section. Table 1 shows the recovery and precision data of the major terpenic acid present in ethanolic OLE. Terpenes recovery ranged between $94.7-96.2 \%$.

Recovery of sugars and phenolics by SPE. Separation of phenols and soluble carbohydrates in olive leaf extract was carried out by solid-phase extraction with Strata SDBL cartridges. A multi-standards solution (sucrose, glucose, mannitol, sorbitol, PHPA, hydroxytyrosol, luteolin-7-O-glucoside and oleuropein) was prepared in Milli-Q deionized water and fractionated following the protocol described in the 2.4 and 2.6 sections. Three independent assays performed in triplicate were carried out, and the efficiency of the recovery and precision of the method were determined (Table 1). The overall recoveries lay between 92.1 and $96.4 \%$ for all the reference compounds, with RSD less than $7.0 \%$. These recoveries are comparable to $100 \%$ at $95 \%$ confidence level $(\mathrm{p}>0.05)$. According to these results, it is clear that Strata SDB-L cartridges allow a very homogeneous recovery of the major bioactive sugars and phenolics of the olive leaf and give confidence in the quantitative evaluation of ethanolic OLE

Linearity, limits of detection and quantification, precision and accuracy of the HPLC methods. The limits of detection (LD) and quantification (LQ) for each analyte under the chromatographic conditions were determined at the signal-to noise ratio $(\mathrm{S} / \mathrm{N})$ of 3 and 10 , respectively. The results of the $\mathrm{F}$ test for comparison of the variance of residuals and the 
variance of the regression indicated that all the reference compounds showed good linearity ( $p$ $\left.<0.05 ; \mathrm{r}^{2}>0.991\right)$ in the concentration range $(0.1-1 \mathrm{mg} / \mathrm{mL})$. The LD for triterpenes, phenols and sugars were 1.8, 2.1 and $2.3 \mu \mathrm{g} / \mathrm{mL}$, respectively. Quality controls at four concentration levels $(0.1,0.2,0.4$ and $0.5 \mathrm{mg} / \mathrm{mL})$ were performed to evaluate intra- and inter-assay precision and accuracy of the methods, with four replicates for each level. The precision of the methods was expressed as relative standard deviations (RSD) for replicate measurements, whereas the accuracy was stated by the percentage of deviation between nominal and calculated concentrations. The analytical procedures were found to be precise with RSD values within $1.9-8.7 \%$ for terpenoids, $2.3-7.7 \%$ for saccharides and $2.6-7.5 \%$ for phenols (intraday assay). On the other hand, the interday RSDs were below 5\% for all the analytes. The overall recoveries lay between 92.0 and $96.4 \%$ for all the reference compounds, with relative standard deviations (RSD) less than $10.0 \%$. These recoveries were not statistically different than $100 \%$ at $95 \%$ confidence level $(\mathrm{p}>0.05)$, which indicated that the established method was accurate enough for the determination of these compounds in olive leaf extract.

Application of the analytical procedure in four olive varieties. After establishing this new procedure for the extraction and analysis of the main bioactive compounds of the olive leaf, we applied it in a comparative study with ethanolic extracts of the four most important Spanish olive cultivars ('Arbequina', 'Hojiblanca', 'Lechin' and 'Picual'). All the olive leaves analyzed came from the same olive orchard, with the same soil, climate and culturing conditions. In addition, the leaves from the central portion of olive branches were collected at the same time (March 2013). Therefore the found differences should be attributable, mainly, to the genetic profile of the olive cultivars.

From Table 2, it can be observed that ethanolic extracts from olive leaf contain high levels of triterpenes, sugars and phenols. The phenolic derivatives are quantitatively the most important group of bioactive compounds. It stands out the 'Picual' cultivar, where phenolics 
represent more than $15 \%$ by weight of dry leaf. 'Hojiblanca' and 'Lechin' leaves show very similar levels (around 11\% DW), whereas 'Arbequina' exhibits the lowest contents of these secoiridoids (ca. 8\% DW). Sugars and alditols, the second group of bioactive compounds in quantitative importance, represent a $4-5 \%$ of the olive leaf dry weight. In this case, the leaves of the 'Picual' and 'Lechin' cultivars are those with the greatest contents, and 'Hojiblanca' displayed the lowest. Finally, our analytical procedure shows that the abundance of triterpenoids was very similar in leaves of the 'Picual', 'Hojiblanca' and 'Lechin' cultivars, where they almost achieved a 5\% DW. The 'Arbequina' leaf had the lowest contents of triterpenes.

Pentacyclic triterpenes in ethanolic OLEs from four Spanish olive cultivars. Figure 3 illustrates an example of the chromatographic analysis of the pentacyclic triterpenoids present in ethanolic OLE. In this chromatogram, it can be observed the presence of very important levels of oleanolic acid, the significant concentration of maslinic acid and lower amounts of ursolic acids and of the dialcohols erythrodiol and uvaol. The Table 3 shows the contents of the different triterpenes in extracts of the four studied Spanish olive cultivars, standing out that they are dependent on the olive variety. As we mentioned, oleanolic acid is the major triterpenoid, with levels that achieved up to 3.2\% leaf DW. 'Hojiblanca' exhibited the greatest content of this triterpenoid, followed by 'Lechin' and 'Picual'. 'Arbequina' is the cultivar with the lower level of oleanolic acid. Also remarkable are the leaf content of maslinic acid, the main triterpenoids in the olive fruit. This compound is present in the 'Picual' leaf at levels around $1.1 \%$ of the dry weight, and in the other three cultivars in the range $0.8-0.9 \%$. Considering the distinction among triterpenic acids and dialcohols, it could be stated that the ethanolic OLEs from 'Picual' leaf are characterized by the highest level of triterpenic acids, whereas those from "Arbequina" exhibit the highest quantities of triterpenic dialcohols. All these data confirm previous results reported by our laboratory using GC-FID for the 
quantification of triterpenoids (Guinda et al., 2010), as well as with those described by other authors (Sánchez-Avila et al., 2007; Sánchez-Avila et al., 2009).

Saccharides and polyols. The soluble carbohydrate composition of the olive leaf differs from that of many other plant species, in which sucrose and sorbitol are the main components. Instead, glucose, fructose, mannitol, sucrose, galactose and inositol were the main sugars found in the leaves and wood of olive trees (Drossopoulos et al., 1988; Tommaso et al., 2000). A typical HPLC-IR profile of the saccharides present in ethanolic OLEs is exposed in the Figure 3. In addition, their quantitative analysis is shown in Table 4. As it can be seen, mannitol is clearly the most abundant saccharide in ethanolic OLEs (65-81\% DW). Sucrose (14-25\%) and glucose (5-9\%) are present in lower concentrations, whereas the rest of the sugars (fructose, galactose, manose or inositol) are almost negligible. These results differ somewhat from previous findings indicating that glucose $(49 \%)$ is the main saccharide in the olive leaf, followed by mannitol (41\%) and fructose (6\%) (Tommaso et al., 2000; GómezGonzález et al., 2010). These differences may be explained by the extracting agent we use (Molasses ethanol $96^{\circ}$ ), which is not optimal for sugars extraction, although it is very adequate for a selective extraction of mannitol.

As in the case of triterpenoids, the saccharide composition of OLEs is dependent of the cultivar. The greatest levels of mannitol were found in ethanolic extracts of 'Picual' and 'Lechin' leaves, with a yielding of 3.9-4.0 grams of the alditol per 100 grams of dry leaf. It is striking the significantly lower levels of mannitol in extracts from the 'Arbequina' cultivar. An agronomic aspect that influences the saccharide composition of the olive leaf in a given time is the irrigation regime. In our study, however, the differences we have found can be attributed almost exclusively to the genetic profiles of each olive cultivar, because, as already mentioned, all leaf samples were collected at the same time in the same orchard, where the soil, climate and culturing conditions were identical. 
Biophenols in ethanolic OLEs. The Table 2 revealed the quantitative importance of phenolic derivatives in ethanolic OLEs. According to our extraction procedure, this group of compounds would represent more than a half of all the bioactive components. The HPLCDAD analysis of these extracts allowed the identification of seven phenolic derivatives: hydroxytyrosol, verbascoside, flavones (luteolin 7-O-glucoside, apigenin 7-O-glucoside), oleuropein, ligstroside and oleuropein-aglycone (Figure 4). All of them have been already reported to occur in the olive leaf (Ucella 2001; Erba and Icier 2010). Oleuropein appears undoubtedly as the major phenolic component of the olive leaf. The quantitative analysis of phenolic derivatives in the ethanolic OLEs is shown in Table 5. The results confirm the prominence of oleuropein, which represents approximately a $56 \%$ of the phenolic fraction in the extracts of the four studied olive leaf cultivars. However, significant differences $(p \geq 0.05)$ were observed in the absolute abundance of these compounds among cultivars. The 'Picual' variety exhibits the greatest amount of phenolics and 'Arbequina' the lowest. The cultivars 'Lechin' and 'Hojiblanca' presented almost identical and intermediate phenolic profile. Further than oleuropein, the contents of luteolin-O-glucoside, ligstroside and hydroxytyrosol were also importants (1-2\% DW). The phenolic profile of the ethanolic OLEs obtained by this method is similar to those exposed by other authors (Savournin et al., 2001; Japón-Lujan et al., 2006) despite they use different ethanol/water ratios in the extracting media, and probably different olive cultivars. On the other hand, an aspect already mentioned in this work that brings strength to the results is the exclusion of factors related to the different source of the olive leaf samples, in terms of geographical origin, soil, climate, culturing regime or harvest time.

We should emphasize the high contents of oleuropein and its derivative hydroxytyrosol in the ethanolic extracts of olive leaf. These specific secoroids from Oleaceae are strongly demanded by the food, cosmetic and pharmaceutical industries. In order to their commercial 
supply, the two main raw sources of these bioactive compounds are the olive leaf and the semi-solid waste from the olive oil industry, known as alperujo. The olive leaf exhibits the greatest levels of oleuropein among all the olive organs. Whereas the concentration of this secoroid in olive oils barely achieves a $0.12 \%$, or in alperujo might reach up to $0.87 \%$, in the olive leaf have been reported oleuropein contents as high as 14\% (Ucella 2001).

A simple, rapid, and reliable analytical procedure for the extraction and analysis of the major bioactive compounds in ethanolic OLE samples: oleuropein, oleanolic acid, and mannitol is developed. The method was characterized by good precision, linearity, and accuracy. The results obtained in this investigation are in agreement with previous research about the presence of oleanolic acid and oleuropein in the olive leaf. We conclude that the established method can be suitable in addition to routine analysis in the control of the processes for obtaining high-added-value compounds from olive leaf. We think that this may contribute to the valorization of the olive grove biomass, which is currently not well profited.

\section{ACKNOWLEDGEMENT}

We are grateful to the "Juan Ramon Guillén" Foundation for the gentle supply of the olive leaves.

\section{REFERENCES}

Andreadou, I., Iliodromitis, E.K., Mikros, E., Constantinou, M., Agalias, A., Magiatis, P., Skaltsounis, A.L., Kamber, E., Tsantili-Kakoulidou, A., Kremastinos, D.T. (2006). The olive constituent oleuropein exhibits anti-ischemic, antioxidative, and hypolipidemic effects in anesthetized rabbits. $J$ Nutr, 136, 2213-2219.

Carluccio, M.A., Siculella, L., Ancora, M.A., Massaro, M., Scoditti, E., Storelli, C., Visioli, F., Distante, A., De Caterina, R. (2003). Olive oil and red wine antioxidant polyphenols inhibit endothelial activation, antiatherogenic properties of Mediterranean diet phytochemicals. Arterioscler Thromb Vasc Biol 23, 622-629. 
Castellano, J.M., Guinda, Á., Rada, M., Delgado, T., Cayuela, J.A. (2013). Biochemical Basis of the Antidiabetic Activity of Oleanolic Acid and Related Pentacyclic Triterpenes. DIABETES 62, 1791-1799.

Drossopoulos, J.B., Niavis, C.A. (1988). Seasonal changes of the metabolites in the leaves, bark and xylem tissues of olive tree (Olea europaea L). II. Carbohydrates. Ann Bot 62, 321327.

Erba, Z., Icier, F. The Importance and Potential Uses of Olive Leaves. (2010). Food Rev Int 26, 319-334. DOI: 10.1080/87559129.2010.496021

Gaspar, P., Neves, A.R., Ramos, A., Gasson, M.J., Shearman, C.A., Santos H. (2004). Engineering Lactococcus lactis for production of mannitol: high yields from food-grade strains deficient in lactate dehydrogenase and the mannitol transport system. Appl Environ Microbiol 70, 1466-1474.

Gómez-González, S., Ruiz-Jiménez, J., Priego-Capote, F., Luque de Castro, M.D. (2010). Qualitative and Quantitative Sugar Profiling in Olive Fruits, Leaves, and Stems by Gas Chromatography-Tandem Mass Spectrometry (GC-MS/MS) after Ultrasound-Assisted Leaching. J Agric Food Chem 58, 12292-12299.

Guidance for industry, Waiver of in Vivo Bioavailability and Bioequivalence Studies for Immediate Release Solid Oral Dosage Forms Based on a Biopharmaceutics Classification System. August (2000), CDER/FDA.

Guinda, Á. (2006). Use of solid residues from olive industry. Grasas y Aceites 57, 42-52.

Guinda, Á., Albi, T., Lanzón, A. Procedimiento para la obtención de ácidos terpénicos a partir de la hoja de Olea europaea. Spanish Patent 2, 160,553, (2001).

Guinda, Á., Rada, M., Delgado, T., Gutiérrez-Adánez, M.P., Castellano, J.M. (2010). Pentacyclic triterpenoids from olive fruit and leaf. J Agric Food Chem 58, 9685-9691.

Japón-Lujan, R., Luque-Rodríguez, J.M., Luque de Castro, M.D. (2006). Dynamic ultrasound-assisted extraction of oleuropein and related polyphenols from olive leaves. $J$ Chromatogr A 1108, 76-82. 
Justino, C., Marque, A.G., Duarte, K.R., Duarte, A.C., Pereira, R., Rocha-Santos, T., Freitas, AC. (2010). Degradation of phenols in olive oil mill wastewater by biological, enzymatic, and photo-Fenton oxidation. Environ Sci Pollut Res 17, 650-656.

Kayce, P., Kırmızıgül, S. (2010). Chemical Constituents of Two Endemic Cephalaria Species. Rec. Nat Prod 4, 141-148.

Liu, J., Sun, H., Wang, X., Mu, D., Liao, H., Zhang, L. (2007). Effects of oleanolic acid and maslinic acid on hyperlipidemia. Drug Dev Res 68, 261-266.

Manzanares, P., Negro, MJ., Oliva, JM., Sáez, F., Ballesteros, I., Ballesteros, M., Cara, C., Castro, E., Ruiz, E. (2011). Different process configurations for bioethanol production from pretreated olive pruning biomass. J Chem Technol Biotechnol 86, 881-887.

Martin, R., Carvalho-Tavares, J., Hernández, M., Arnés, M., Ruiz-Gutiérrez, V., Nieto, ML. (2010). Beneficial effects of oleanolic acid in an experimental model of multiple sclerosis: A potential therapeutic role. Biochem Pharmacol 79, 198-208.

Obied, H.K., Prenzler, P.D., Omar, S.H., Ismael, R., Servili, M., Esposto, S., Taticchi, A., Selvaggini, R., Urbani, S. (2012) Pharmacology of olive biophenols, in Fishbein, J.C. Heilman, J.M. (Eds.), Advances in Molecular Toxicology (pp. 195-223) Amsterdam:Elsevier.

Rada, M., Guinda, A., Cayuela, J.A. (2007). Solid/liquid extraction and isolation by molecular distillation of hydroxytyrosol from Olea europaea L. leaves. Eur J Lipid Sci Technol 109, 1071-1076.

Rada, M., Ruiz-Gutiérrez, V., Guinda, Á. (2011). Determination of Triterpenic Acids in Human Serum by High-Performance Liquid Chromatography: Triterpenoid Interaction with Serum Protein. J Agric Food Chem 59, 2308-2313.

Romani, A., Baldi, A., Tattini, M., Vincieri, E.F. (1994). Extraction, Purification Procedures and HPLC-RI Analysis of Carbohydrates in Olive (Olea europaea L.) Plants. Chromatographia 39, 35-39.

Sánchez-Avila, N., Priego, F., Luque de Castro, M.D. (2007). Ultrasound assisted extraction and silylation prior to gas chromatography-mass spectrometry for the characterization of the triterpenic fraction in olive leaves. J Chromatogr A 1165, 158-165. 
Sánchez-Avila, N., Priego, F., Ruiz-Jiménez, J., Luque de Castro, M.D. (2009). Fast and selective determination of triterpenic compounds in olive leaves by liquid chromatographytandem mass spectrometry with multiple reaction monitoring after microwave-assisted extraction. Talanta 78, 40-48.

Savournin, C., Baghdikian, B., Elias, R., Dargouth-Kesraoui, F., Boukef, K., Balansard, G. (2001). Rapid high-performance liquid chromatography analysis for the quantitative determination of oleuropein in Olea europaea leaves. J Agri Food Chem 49, 618-621.

Shanmugam, M.K., Dai, X., Kumar, AP., Tan, B.K.H., Sethi, G., Bishayee, A. (2014). Oleanolic acid and its synthetic derivatives for the prevention and therapy of cancer: Preclinical and clinical evidence. Cancer Letters 346, 206-216.

Silva, S., Gomes, L., Leitao, F., Coelho, AV., Vilas, Boas, L. (2006). Phenolic compounds and antioxidant activity of Olea europaea L. fruits and leaves. Int J Food Sci Tech 12, 385396.

Singh, I., Mok, I.M., Christensen, A.M., Turner, A.H., Hawley, J.A. (2008). The effects of polyphenols in olive leaves on platelet function. Nutr Metab Cardiovas 18, 127-132.

Tabera-Galván, J.J., Ruiz-Rodríguez, A., Señoráns, F.J., Ibáñez, E., Reglero, J., Albi, T., Lanzón, A., Pérez-Camino, M.C., Guinda, A., Rada M. (2005) Procedimiento para obtener compuestos de alto valor añadido a partir de hoja de olivo. WO/2005/075614.

Tommaso, R., Cataldi, I., Margiotta, G., Iasi, L., Di Chio, B., Xiloyannis, C., Bufo, SA. (2009). Determination of Sugar Compounds in Olive Plant Extracts by Anion-Exchange Chromatography with Pulsed Amperometric Detection. Anal Chem 72, 3902-3907.

Tripoli, E., Giammanco, M., Tabacchi, G., Di Majo, D., Giammanco, S., La Guardia M. (2005). The phenolic composition of olive oil: structure, biological activity, and beneficial effects on human health. Nutr Res Rev 18, 98-112.

Tsai, S.J., Yin, M.C. (2008). Antioxidative and anti-inflammatory protection of oleanolic acid and ursolic acid in PC12 cells. J Food Sci 73, 174-178.

Ucella, N. (2001). Olive biophenols: novel ethnic and technological approach. Trends in Food Sci \& Tech 11, 328-339. 
Visioli, F., Poli, A., Galli, C. (2002). Antioxidant and other biological activities of phenols from olives and olive oil. Med Res Rev 22, 65-75.

\section{FIGURE CAPTIONS}

Figure 1. Flow diagram of the analytical procedure established for the determination of bioactive compounds in ethanolic extracts of olive leaves (OLE).

Figure 2. Example of a HPLC-UV chromatogram of triterpenic compounds from ethanolic extract of olive leaves. IS (internal standard) asiatic acid, 1. maslinic acid, 2. oleanolic acid, 3. ursolic acid, 4. erythrodiol and 5. uvaol.

Figure 3. Example of a HPLC-IR chromatogram of sugars from ethanolic extract of olive leaves. 1. sucrose, 2. glucose, 3. mannitol, IS (internal standard) sorbitol.

Figure 4. Example of a HPLC-DAD chromatogram of the phenolic compounds from ethanolic extract of olive leaves. 1. hydroxytyrosol; IS (internal standard) PHPA; 2. verbascoside; 3. luteolin-7-O-glucoside; 4. apigenin-7-glucoside; 5. oleuropein; 6. ligstroside; 7. oleuropein aglycone. 
Table 1. Recovery and precision data of mayor bio-compounds

\begin{tabular}{|c|c|c|c|c|c|c|c|c|}
\hline \multicolumn{3}{|c|}{ oleanolic acid* } & \multicolumn{3}{|c|}{ oleuropein } & \multicolumn{3}{|c|}{ mannitol $^{\#}$} \\
\hline $\begin{array}{l}\text { concentration } \\
(\mathrm{mg} / \mathrm{ml})\end{array}$ & $\begin{array}{c}\text { mean } \\
(\%)\end{array}$ & $\begin{array}{c}\text { RSD } \\
(\%)\end{array}$ & $\begin{array}{l}\text { concentration } \\
(\mathrm{mg} / \mathrm{ml})\end{array}$ & $\begin{array}{c}\text { mean } \\
(\%)\end{array}$ & $\begin{array}{c}\text { RSD } \\
(\%)\end{array}$ & $\begin{array}{l}\text { concentration } \\
(\mathrm{mg} / \mathrm{ml})\end{array}$ & $\begin{array}{c}\text { mean } \\
(\%)\end{array}$ & $\begin{array}{l}\text { RSD } \\
(\%)\end{array}$ \\
\hline 0,25 & 96.2 & 4.7 & 0,1 & 96.2 & 5.1 & 0,1 & 95.0 & 5.4 \\
\hline 0,50 & 96.4 & 5.2 & 0,5 & 96.4 & 5.5 & 0,5 & 94.6 & 5.7 \\
\hline 1,00 & 95.5 & 6.2 & 1 & 95.5 & 6.3 & 1 & 94.5 & 6.1 \\
\hline
\end{tabular}

*filtration recovery; ${ }^{*}$ SPE recovery

Table 2. Major bio-compounds in olive leaves of Spanish cultivars

\begin{tabular}{lccc}
\hline cultivar & phenols & Total- Biocompounds (\% DW) & sugars \\
\hline Picual & $15,80 \pm 0,96^{\mathrm{a}}$ & $5,24 \pm 0,30^{\mathrm{a}}$ & terpenes \\
Hojiblanca & $11,77 \pm 0,70^{\mathrm{b}}$ & $3,94 \pm 0,36^{\mathrm{b}}$ & $4,73 \pm 0,35^{\mathrm{a}}$ \\
Arbequina & $8,02 \pm 0,45^{\mathrm{c}}$ & $4,50 \pm 0,44^{\mathrm{c}}$ & $4,71 \pm 0,37^{\mathrm{a}}$ \\
Lechin & $11,27 \pm 0,58^{\mathrm{b}}$ & $5,38 \pm 0,37^{\mathrm{a}}$ & $3,44 \pm 0,28^{\mathrm{b}}$ \\
\hline
\end{tabular}

"Results are referenced to leaf dry weight and expressed as mean (SD of four independent samples of each variety analyzed in duplicate. (a-c). Results in a row not sharing a common letter are significantly different $(p>0.05)$.

Table 3. Pentacyclic triterpenes (\% DW) in olive leaves of Spanish cultivars

\begin{tabular}{lccccc}
\hline cultivar & erythrodiol & uvaol & oleanolic acid & ursolic acid & maslinic acid \\
\hline Picual & $0,08 \pm 0,01^{\mathrm{a}}$ & $0,07 \pm 0,01^{\mathrm{a}}$ & $3,10 \pm 0,29^{\mathrm{a}}$ & $0,41 \pm 0,03^{\mathrm{a}}$ & $1,07 \pm 0,10^{\mathrm{a}}$ \\
Hojiblanca & $0,10 \pm 0,03^{\mathrm{a}}$ & $0,12 \pm 0,03^{\mathrm{b}}$ & $3,27 \pm 0,23^{\mathrm{a}}$ & $0,38 \pm 0,02^{\mathrm{a}}$ & $0,84 \pm 0,09^{\mathrm{b}}$ \\
Arbequina & $0,14 \pm 0,05^{\mathrm{b}}$ & $0,14 \pm 0,03^{\mathrm{b}}$ & $2,16 \pm 0,18^{\mathrm{b}}$ & $0,21 \pm 0,01^{\mathrm{b}}$ & $0,79 \pm 0,09^{\mathrm{b}}$ \\
Lechin & $0,11 \pm 0,02^{\mathrm{a}}$ & $0,11 \pm 0,02^{\mathrm{b}}$ & $3,18 \pm 0,42^{\mathrm{a}}$ & $0,40 \pm 0,03^{\mathrm{a}}$ & $0,91 \pm 0,10^{\mathrm{b}}$ \\
\hline
\end{tabular}

\# Results are referenced to leaf dry weight and expressed as mean (SD of four independent samples of each variety analyzed in duplicate. $(a-c)$ Results in a row not sharing a common letter are significantly different $(\mathrm{p}>0.05)$. 
Table 4. Saccharides and polyols (\% DW) in olive leaves of Spanish cultivars

\begin{tabular}{lccc}
\hline cultivar & sucrose & glucose & mannitol \\
\hline Picual & $0,98 \pm 0,06^{\mathrm{a}}$ & $0,29 \pm 0,02^{\mathrm{a}}$ & $3,97 \pm 0,23^{\mathrm{a}}$ \\
Hojiblanca & $0,99 \pm 0,05^{\mathrm{a}}$ & $0,37 \pm 0,04^{\mathrm{b}}$ & $2,58 \pm 0,29^{\mathrm{b}}$ \\
Arbequina & $0,62 \pm 0,08^{\mathrm{b}}$ & $0,22 \pm 0,01^{\mathrm{c}}$ & $3,66 \pm 0,38^{\mathrm{a}}$ \\
Lechin & $1,03 \pm 0,05^{\mathrm{a}}$ & $0,46 \pm 0,03^{\mathrm{d}}$ & $3,89 \pm 0,31^{\mathrm{a}}$ \\
\hline
\end{tabular}

\#Results are referenced to leaf dry weight and expressed as mean (SD of four independent samples of each variety analyzed in duplicate. $(\mathrm{a}-\mathrm{c})$ Results in a row not sharing a common letter are significantly different $(\mathrm{p}>0.05)$. 
Table 5. Biophenols (\% DW) in olive leaves of Spanish cultivars

\begin{tabular}{|c|c|c|c|c|c|c|c|}
\hline cultivar & hydroxytyrosol & verbascoside & $\begin{array}{c}\text { luteolin-O-glucoside } \\
\text {-glucoside }\end{array}$ & apigenin7-O-glucoside & oleuropein & ligstroside & oleuropein-aglycone \\
\hline Picual & $1,12 \pm 0,20^{\mathrm{a}}$ & $0,78 \pm 0,12^{\mathrm{a}}$ & $2,00 \pm 0,38^{\mathrm{a}}$ & $0,65 \pm 0,10^{\mathrm{a}}$ & $8,72 \pm 0,82^{\mathrm{a}}$ & $1,79 \pm 0,25^{\mathrm{a}}$ & $0,74 \pm 0,10^{\mathrm{a}}$ \\
\hline Hojiblanca & $0,78 \pm 0,10^{\mathrm{b}}$ & $0,59 \pm 0,08^{\mathrm{b}}$ & $1,44 \pm 0,30^{\mathrm{b}}$ & $0,49 \pm 0,07^{\mathrm{b}}$ & $6,57 \pm 0,56^{\mathrm{b}}$ & $1,34 \pm 0,18^{\mathrm{b}}$ & $0,56 \pm 0,08^{\mathrm{b}}$ \\
\hline Arbequina & $0,53 \pm 0,08^{c}$ & $0,40 \pm 0,07^{\mathrm{c}}$ & $1,01 \pm 0,14^{\mathrm{c}}$ & $0,33 \pm 0,07^{\mathrm{c}}$ & $4,46 \pm 0,34^{\mathrm{c}}$ & $0,91 \pm 0,17^{\mathrm{c}}$ & $0,38 \pm 0,05^{\mathrm{c}}$ \\
\hline Lechin & $0,94 \pm 0,16^{\mathrm{ab}}$ & $0,55 \pm 0,08^{\mathrm{b}}$ & $1,42 \pm 0,30^{\mathrm{b}}$ & $0,46 \pm 0,07^{\mathrm{b}}$ & $6,13 \pm 0,43^{\mathrm{b}}$ & $1,25 \pm 0,09^{\mathrm{b}}$ & $0,52 \pm 0,08^{\mathrm{b}}$ \\
\hline
\end{tabular}

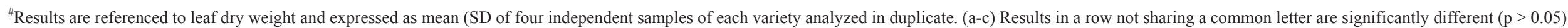




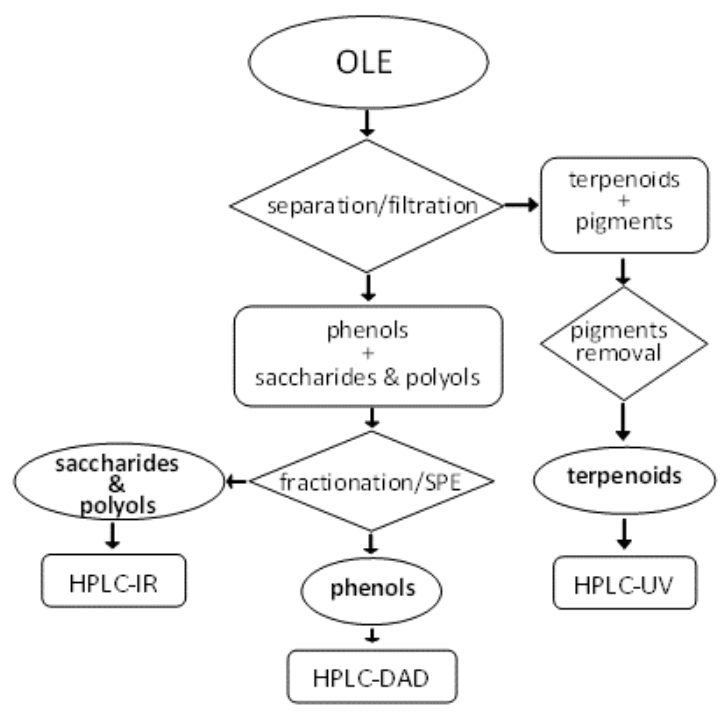

Figure 1

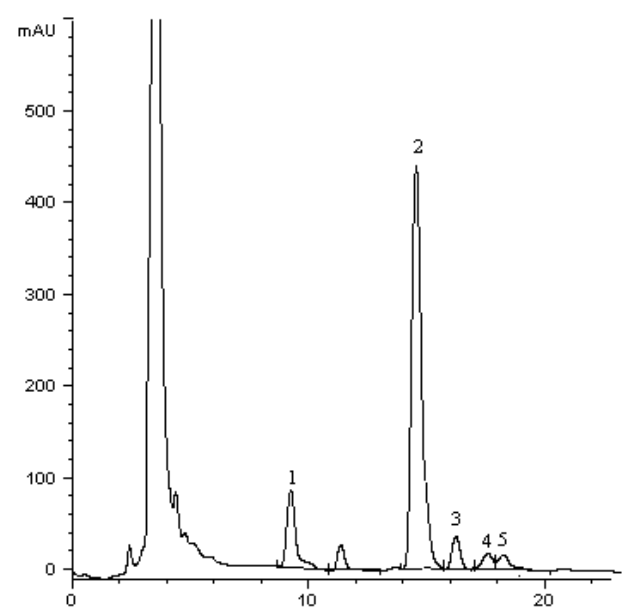

Figure 2 


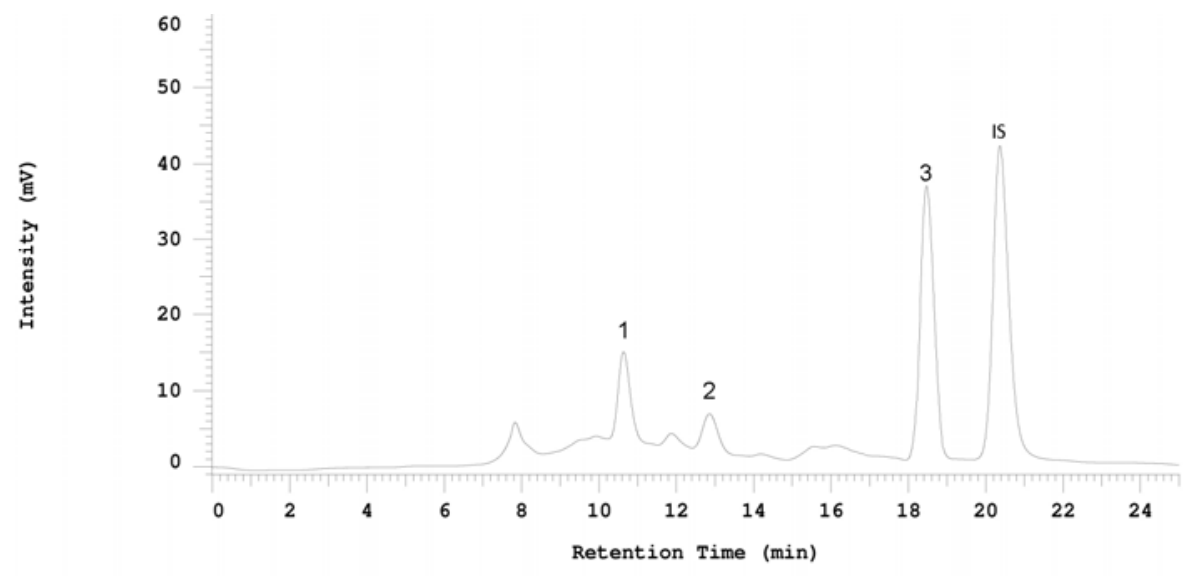

Figure 3

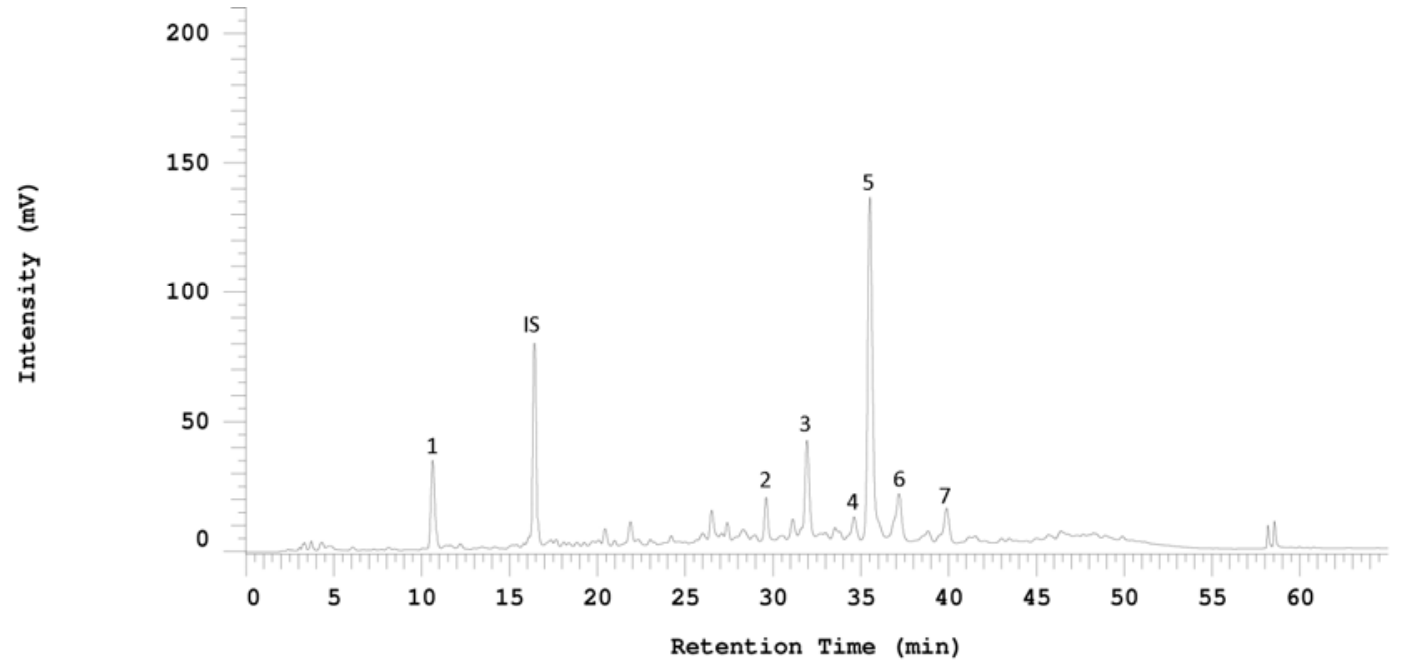

Figure 4 